Short title: ALEXITHYMIA, NEGATIVE AFFECT, AND DISORDERED EATING

\title{
Direct and indirect effects of alexithymia on eating disorder symptoms in a non-clinical female sample: determining the role of negative affect
}

\author{
Deborah J. Wallis ${ }^{1 \mathrm{a}}$ and Nathan Ridout ${ }^{\mathrm{b} *}$
}

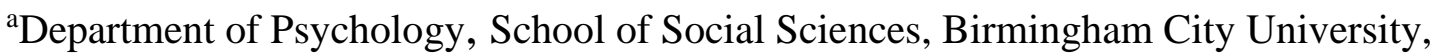
Birmingham, B4 7BD. Deborah.Wallis@ bcu.ac.uk

${ }^{\mathrm{b}}$ School of Psychology, College of Health and Life Sciences, Aston University, Birmingham, UK, B4 7ET n.ridout@ aston.ac.uk

\author{
*Address for correspondence \\ Dr Nathan Ridout \\ School of Psychology \\ College of Health \& Life Sciences \\ Aston University \\ Aston Triangle \\ Birmingham, UK \\ B4 7ET \\ n.ridout@aston.ac.uk
}

Word count: 5385 (including tables, and table/ figure legends)

\footnotetext{
${ }^{1}$ DW and NR jointly conceived and designed the study. NR conducted the data analysis. DW and NR jointly contributed to the final draft of the manuscript.
} 


\begin{abstract}
Alexithymia, a multifaceted personality construct, characterised by difficulties identifying and describing one's feelings, and by an externally focused cognitive style. Alexithymia is risk factor for negative affect and disordered eating. Previous work involving patients with anorexia nervosa revealed that high levels of alexithymia were directly linked to eating disorder symptoms and also indirectly linked via negative affect. Our aim was to establish if these findings generalised to subclinical disordered eating symptoms. A non-clinical sample of females ( $\mathrm{n}=206)$ completed measures of depression, anxiety, alexithymia, and disordered eating. As expected, negative affect (combined depression and anxiety) mediated the effect of alexithymia (difficulty identifying feelings and difficulty describing feelings) on disordered eating symptoms (drive for thinness, bulimia, and body dissatisfaction). However, also as expected, direct effects of these alexithymia facets on disordered eating were still evident after controlling for negative mood. Our findings confirm that the relationships observed in patients with clinically diagnosed eating disorders are also evident in those with subclinical disordered eating. Targeted interventions to reduce deficits in recognising and describing one's feelings could potentially ameliorate disordered eating in 'at risk' participants.
\end{abstract}

Keywords: emotional awareness, emotional language, affect, eating disorders, depression, mediation 


\section{Introduction}

Alexithymia (ALX) is a multi-faceted construct characterised by problems identifying one's feelings and distinguishing between feelings and bodily sensations, difficulties in verbally describing one's feelings to others, a lack of imagination and fantasies, and an externally focused cognitive style (Taylor \& Bagby, 2000). The Toronto Alexithymia Scale (TAS-20; Bagby, Parker \& Taylor, 1994), which is the most widely used self-report measure of this construct, measures three facets of alexithymia: difficulties identifying feelings (DIF; e.g. "I am often confused about what emotion I am feeling"), difficulty describing feelings (DDF; e.g. "It is difficult for me to find the right words for my feelings"), and externally oriented thinking (EOT; e.g. "I prefer to speak to people about their daily activities rather than their emotions"). Scores on the three subscales are summed to provide a total alexithymia score. Based on the suggested cut-off (Total TAS-20 >61; Bagby et al., 1994) it has been reported that around 10\% of the general population are alexithymic (Franz et al., 2008; Matilla, Salminen, Nummi \& Joukamaa, 2006). However, significantly higher prevalence has been shown in psychiatric patients. For example, Taylor, Parker, Bagby and Acklin (1992) reported that around $40 \%$ of a sample of psychiatric patients were classified as alexithymic. Alexithymia has been linked to a wide range of psychopathology (Grabe, Spitzer \& Freyberger, 2004). Importantly, evidence supports that alexithymia is a stable trait that predisposes individuals to psychopathology, rather than a state phenomenon of psychological distress (Tolmunen et al., 2011).

Notably, high levels of alexithymia have been reported in patients with eating disorders: anorexia nervosa (Abbate-Daga et al, 2015; Eizaguirre et al, 2004), bulimia nervosa (Beales \& Dolton, 2000; Speranza et al, 2005) and binge eating disorder (Carano et al., 2012; Pinaquy et al, 2003). In a recent review, Morie and Ridout (2018) reported that rates of alexithymia in patients with eating disorders ranged between $32 \%$ and $69 \%$ but were largely 
consistent across the different eating disorders. In addition to higher overall levels of alexithymia, direct links have been reported between alexithymia, particularly the subscales of DIF and DDF, and symptoms of disordered eating in patients with eating disorders (Carano et al., 2012; Courty et al., 2015; Eizaguirre et al, 2004, Tchanturia et al., 2012). This suggests that alexithymia might play a role in the development of disordered eating. Findings that levels of alexithymia are lower in patients in remission from eating disorders (Storch et al, 2011) does not support this assertion. However, findings that recovered patients still report significantly higher levels alexithymia than do healthy controls (Courty et al., 2015; Tchanturia et al., 2012) suggest that alexithymia might be a stable characteristic of individuals who are prone to disordered eating. Consistent with this notion, Speranza et al. (2007) conducted a 3-year prognostic study and reported that alexithymia (scores on the DIF subscale) predicted the persistence of symptoms in patients with anorexia and bulimia nervosa. Evidence of links between alexithymia and disordered eating in non-clinical samples is also consistent with this notion (Apsalan et al., 2015; de Beradis et al., 2007; Ridout, Thom \& Wallis, 2010; Ridout, Wallis, Autwal \& Sellis, 2012). Interestingly, Morie and Ridout (2018) confirmed that in clinical and non-clinical samples disordered eating is only linked to scores on two of the three subscales of alexithymia: difficulty identifying feelings and difficulty describing feelings, and not externally oriented thinking.

Elevated levels of alexithymia have also been reported in depressed individuals (see review by Honkalampi et al., 2018). For example, Leweke, Leichsenring, Kruse and Hermes (2011) reported that $27 \%$ of a sample of depressed patients met criteria (TAS-20 >61) for alexithymia, which is more than double the prevalence rate (10\%) reported in the general population (Franz et al, 2008). Furthermore, alexithymia, particularly DIF and DDF, has been linked to the severity of depressive symptoms (Conrad et al., 2009; Leweke et al., 2012; Luca, Luca \& Calandra, 2013). Interestingly, associations between alexithymia and 
depressive symptoms have been established within the general population (Honkalampi et al, 2000). As with eating disorders, levels of alexithymia in depressed patients tend to reduce upon remission, but recovered patients still exhibit greater alexithymia than do healthy controls (Gunther et al., 2016; Luminet et al., 2001), which suggests that alexithymia is stable characteristic of individuals who are at risk of depression. In line with this proposal, there is evidence that alexithymia is a risk factor for depression. For example, in a cross-sectional study, Gilanifar and Delava (2016) reported that alexithymia predicted depression in a sample of pregnant women. However, stronger evidence comes from longitudinal studies (Gunther et al, 2016). For example, Kojiama et al (2007) reported that, independent of baseline depression, alexithymia predicted long-term depressive symptoms in a sample of patients on haemodialysis.

Given that depression is a risk factor for the development of eating disorders (Jacobi et al., 2011, Stice, Marti \& Durant, 2011; Stice, Gau, Rhode \& Shaw, 2017), it has been suggested that the links between alexithymia and disordered eating might be a consequence of concurrent depression (Corcos et al., 2000; Eizaguirre et al., 2004; Speranza et al., 2005). Torres et al. (2015) conducted a mediation analysis in a sample of patients with anorexia nervosa to determine if alexithymia influenced eating disorder symptoms directly and/ or indirectly via depression. Their findings confirmed that scores on the DDF subscale were only indirectly linked to a diagnosis of anorexia nervosa, via depression. There was also evidence of an indirect influence of DIF on a diagnosis of anorexia, via depression. However, DIF also directly influenced diagnosis of anorexia independently of depression. This has important implications for the treatment of eating disorders, as it suggests that simply addressing concomitant depression in patients with anorexia nervosa is not sufficient to reduce the symptoms of eating disorders. Furthermore, it suggests there might be value in targeted interventions to improve emotional awareness in patients with eating disorders. 
Consistent with this argument, Clyne et al. (2010) demonstrated that an adjunctive intervention to improve emotional awareness was more effective in treating binge eating disorders than standard treatments (e.g. antidepressants and CBT) alone.

Given the evidence of relationships between alexithymia, depression and disordered eating within the healthy population (Apsalan et al., 2015; de Beradis et al., 2007; Honkalampi et al., 2000; Ridout et al, 2010; 2012) it is important to establish if alexithymia directly influences disordered eating in healthy participants and whether this influence is mediated by depression.

Another potential mediating factor that needs to be considered is anxiety, as individuals with high levels of anxiety exhibit higher rates of alexithymia (Leweke et al., 2012) and alexithymia (TAS-20) scores, particularly DIF, have been linked to severity of anxiety symptoms (Conrad et al., 2009; Grabe et al., 2004). Anxiety is also considered to be a risk factor for the development of disordered eating (Smith et al., 2018; Strober, 2004) as eating disorders are often preceded by anxiety disorders (Swinbourne \& Touyz, 2007; Zerwas et al., 2013). In line with this notion, Pink et al (2019) reported that, in a healthy non-clinical sample, negative affect (a combined factor derived from depression and anxiety) mediated the influence of DIF on body mass index via emotional eating.

\subsection{Overview and predictions}

From the above it can be argued that alexithymia is a stable personality trait that is a risk factor for the development of psychopathological symptoms (depression, anxiety, and disordered eating). As negative affect tends to precede eating disorders, it is plausible that alexithymia might lead to disordered eating by increasing negative affect. With this in mind, 
the aim of the current study was to determine if negative affect (depression \& anxiety) ${ }^{2}$ mediates the influence of alexithymia on symptoms of disordered eating in a non-clinical sample (see mediation model illustrated in Figure 1).

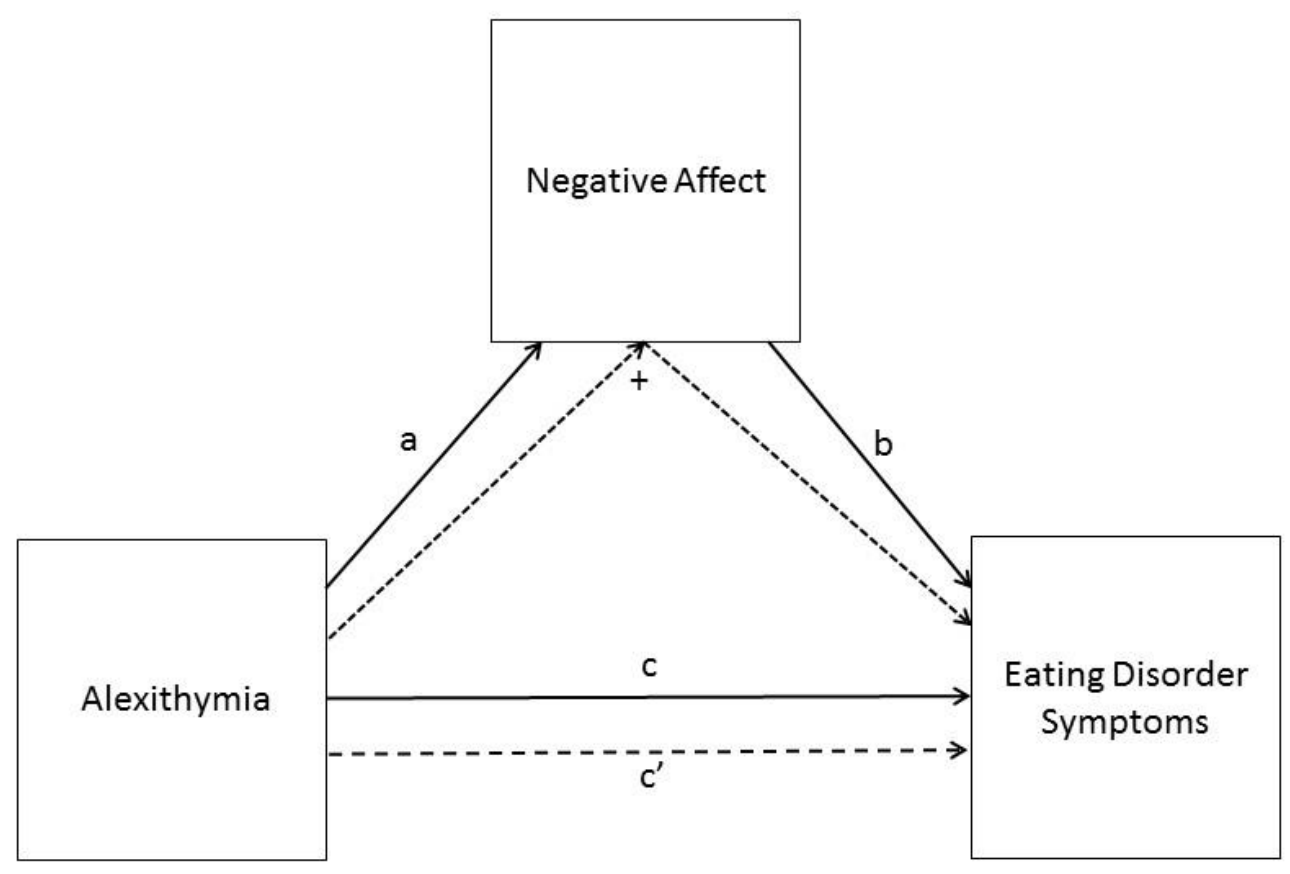

Figure 1. Proposed mediation model illustrating the direct pathway (c') between alexithymia and disordered eating, and the indirect pathway (+) via the mediator (negative affect).

A sample of healthy female undergraduates completed measures of alexithymia, depression, anxiety, and disordered eating. We assumed that the pattern in non-clinical individuals would be consistent with the findings in clinically diagnosed patients (Torres et al., 2015). Thus, it was predicted that negative affect would mediate $(+)$ the association between alexithymia

\footnotetext{
${ }^{2}$ In line with Pink et al. (2018) we combined depression and anxiety scores into a single factor of negative affect.
} 
(DIF and DDF) and disordered eating, but a direct effect (c') of DIF on disordered eating would still be observed.

\section{Method}

\subsection{Participants}

Two-hundred and six female undergraduate students with no history (self-reported) of eating or mood disorders (depression \& anxiety) were recruited from the undergraduate populations of two UK Universities from the Midlands and took part for course credit. The mean age of the participants was 24.20 ( $\mathrm{SD}=6.7$; range=18 to 54$)$. The study was approved by the research ethics committees of both institutions.

\subsection{Measures}

The Toronto Alexithymia Scale (TAS-20; Bagby, Taylor \& Parker, 1994) is a 20-item selfreport measure assessing three facets of alexithymia: difficulty identifying feelings (DIF; e.g. "I have feelings that I can't quite identify"), difficulty describing feelings (DDF; e.g. "It is difficult for me to find the right words for my feelings" and externally oriented thinking (EOT; e.g. "I prefer talking to people about their daily activities rather than their feelings"). Participants indicate the extent to which each item describes them using a 5-point Likert scale (1=strongly disagree, $5=$ strongly agree). Scores on the subscales range between 7-35 (DIF), 5-25 (DDF) and 8-40 (EOT) and are summed to give a total TAS-20 score, which ranges between 20 and 100, with higher scores indicating greater alexithymia. The TAS-20 has been shown to be valid (Bagby et al, 1994) and reliable in student samples (e.g. Pink et al., 2019). The Hospital Anxiety and Depression scale (Zigmond \& Snaith, 1983) is a 14-item measure of self-reported depression and anxiety. Each item consists of a statement relating to a symptom of depression (e.g., "I feel as if I am slowed down") or anxiety (e.g., "I feel tense or wound up" and participants indicate the frequency that they experience that symptom using a 
4-point Likert scale. Scores for each item range from 0-3, and for each subscale between 0-21 with higher score equating to greater depression or anxiety. The HADS is a valid and reliable measure of depression and anxiety (Bjelland, Dahl, Haug, \& Neckelmann, 2002).

Three subscales from the Eating Disorders Inventory-II (EDI-II; Garner, 1991) were used to measure self-reported symptoms of disordered eating: drive for thinness (DFT; e.g. "I am terrified of gaining weight"), bulimia (Bul; e.g. "I have gone on eating binges where I have felt that I could not stop") and body-dissatisfaction (BD; e.g. "I think that my stomach is too big"). Participants rate the extent to which each statement is true of them using a 6-point Likert scale (ranging from always to never). All items are scored from 0-3 (from least to most severe disordered eating). Responses indicating the most severe symptoms are scored 3, 2 and 1 respectively, whilst the remaining three responses are scored zero. Scores on the DFT and Bul subscales range between 0 and 21, and scores on the BD subscale range between 0 and 27. These scales have been shown to have good reliability in student samples (Ridout et al, 2012; Sharpe et al., 2016).

\subsection{Procedure}

Volunteers attended individual appointments in a private room within the psychology laboratories at the two universities. Having given full written informed consent, participants completed printed copies of the HADS, TAS-20 and EDI-II in a counterbalanced order.

\subsection{Data analysis}

Data were analysed using IBM SPSS (v26) and v3.5 of PROCESS (Hayes, 2017). All data were treated as continuous variables. Pearson correlations were used to determine the significance of the associations between variables. As preliminary analysis revealed that depression and anxiety were both significantly linked to alexithymia and eating disorder symptoms (EDI) we conducted a factor analysis on depression and anxiety scores to create a 
single factor (negative affect). PROCESS (model 4) was then used to assess the direct and indirect effects of alexithymia on disordered eating symptoms with negative affect entered as the mediator. This procedure involved bootstrapping (5,000 iterations) to generate biascorrected 95\% confidence intervals (CI) for each effect, which were considered significant when the upper and lower bound did not span zero. This method has been shown to effectively control for Type 1 errors (Preacher \& Hayes, 2008).

\section{Results}

\subsection{Participant Characteristics}

Comparison of the mean EDI scores from the current study (presented in Table 1) with the norms reported in a large non-clinical student sample (Limbert, 2004) revealed that our sample scored significantly higher on all EDI subscales: DFT (mean difference=1.87), $\mathrm{t}(205)=4.22, \mathrm{p}<.001 ;$ Bul (mean difference $=.64), \mathrm{t}(205)=2.61, \mathrm{p}<.01$; and BD (mean difference $=1.43), \mathrm{t}(205)=2.31, \mathrm{p}<.05$. However, importantly, comparison of the current scores with the norms for a clinical sample (Brewin et al, 2014) revealed that the current scores were significantly lower on all subscales of the EDI: DFT (mean difference=-8.85), $\mathrm{t}(205)=19.97, \mathrm{p}<.001 ;$ Bul (mean difference=-4.86), $\mathrm{t}(205)=19.86, \mathrm{p}<.001$, and BD (mean difference=-7.28), $\mathrm{t}(205)=1.77, \mathrm{p}<.001$.

Comparison of the mean TAS-20 total score with a recent UK student sample (Pink et al., 2019) revealed that our sample scored significantly higher, mean difference $=2.65$, $\mathrm{t}(205)=2.56, \mathrm{p}<.05$. However, importantly, the current TAS-20 score is significantly lower (mean difference $=-13.32$ ) than that reported in a sample of clinically diagnosed patients with eating disorders (Torres et al, 2015), $\mathrm{t}(205)=13.8, \mathrm{p}<.001$. Comparison of depression and anxiety scores from the current study with a large UK sample of undergraduate students (Andrews \& Wilding, 2004) revealed that the current sample was significantly less anxious 
(mean difference $=2$ ) than the previous sample, $t(205)=5.99, \mathrm{p}<.001$. However, the two samples did not differ in their levels of depression (mean difference=.2), $\mathrm{t}(205)=.96, \mathrm{p}=.34$. Taken together the pattern is consistent with our conception of the current sample as nonclinical.

Table 1. Participant characteristics: mean values for age, mood, eating disorder symptoms, and alexithymia (standard deviations are presented in parentheses).

\begin{tabular}{lcc}
\hline $\mathrm{n}=206$ & Mean (SD) & Range \\
\hline Age & $24.2(6.7)$ & $18-54$ \\
\hline Alexithymia (TAS-20) & $49.49(14.9)$ & $23-96$ \\
Difficulty describing feelings (DDF) & $12.5(4.4)$ & $4-24$ \\
Difficulty identifying feelings (DIF) & $15.54(5.9)$ & $7-35$ \\
Externally oriented thinking (TAS-EOT) & $21.40(8.7)$ & $9-57$ \\
\hline Eating Disorders Inventory (Total) & $18.6(16.33)$ & $0-72$ \\
Drive for Thinness (DFT) & $5.55(6.4)$ & $0-21$ \\
Bulimia (Bul) & $2.1(3.5)$ & $0-21$ \\
Body Dissatisfaction (BD) & $11.23(8.9)$ & $0-30$ \\
\hline Anxiety (HADS) & $7.42(4.8)$ & $0-20$ \\
Depression (HADS) & $4.1(3.7)$ & \\
\hline
\end{tabular}




\subsection{Relationships between age, mood, alexithymia, and disordered eating}

Correlational analyses (see Table 2) revealed that eating disorder symptoms (indexed by total and subscale scores on the EDI) were significantly related to alexithymia (total TAS-20 and DDF \& DIF subscale scores) and mood (depression \& anxiety). There were also significant associations between alexithymia and mood. It is notable that age was significantly related to alexithymia, eating disorder symptoms and mood. Therefore, age was included as a covariate in the mediation analyses.

Table 2. Correlation coefficients for the relationships between age, mood, alexithymia and eating disorder symptoms.

\begin{tabular}{|c|c|c|c|c|c|c|c|c|c|c|c|}
\hline Variable & 1 & 2 & 3 & 4 & 5 & 6 & 7 & 8 & 9 & 10 & 11 \\
\hline 1. Age & 1 & -.12 & -.04 & -.04 & $-.16^{*}$ & $.19 * *$ & .08 & $.21 * *$ & $.203 * *$ & .08 & $.21^{* * *}$ \\
\hline 2. TAS-20 & & 1 & $.79 * * *$ & $.75^{* * * *}$ & $.80 * * *$ & $.34 * * * *$ & $.36^{* * * *}$ & $.24 * * * *$ & $.29 * * *$ & $.26^{* * * *}$ & $.45 * * *$ \\
\hline 3. DDF & & & 1 & $.69 * * *$ & $.39 * * *$ & $.42^{* * * *}$ & $.43^{* * * *}$ & $.29 * * * *$ & $.37 * * *$ & $.37^{* * * *}$ & $.49 * * *$ \\
\hline 4. DIF & & & & 1 & $.26 * * *$ & $.48^{* * * *}$ & $.50^{* * * *}$ & $.41^{* * * *}$ & $.36 * * *$ & $.58^{* * * *}$ & $.54 * * *$ \\
\hline 5. EOT & & & & & 1 & .05 & .06 & -.01 & .06 & -.13 & $.15^{*}$ \\
\hline 6. EDI & & & & & & 1 & $.88^{* * * *}$ & $.64 * * *$ & $.91 * * *$ & $.46^{* * * *}$ & $.61 * * *$ \\
\hline 7. DFT & & & & & & & 1 & $.52 * * *$ & $.70 * * *$ & $.40^{* * * *}$ & $.52 * * *$ \\
\hline 8. Bul & & & & & & & & 1 & $.42 * * *$ & $.45^{* * * *}$ & $.50 * * *$ \\
\hline 9. BD & & & & & & & & & 1 & $.36^{* * * *}$ & $.53 * * *$ \\
\hline 10. Anx & & & & & & & & & & 1 & $.604 * * *$ \\
\hline 11. Dep & & & & & & & & & & & 1 \\
\hline
\end{tabular}

TAS-20 = Toronto Alexithymia Scale; DDF= difficulty describing feelings (TAS-20); DIF= difficulty identifying feelings (TAS-20); EOT= externally oriented thinking (TAS-20); EDI= Eating Disorders Inventory; DFT $=$ drive for thinness $(\mathrm{EDI}) ; \mathrm{Bul}=$ Bulimia $(\mathrm{EDI}) ; \mathrm{BD}=$ body dissatisfaction $(\mathrm{EDI}) ;$ Anx $=$ Hospital Anxiety and Depression Scale - anxiety subscale, and Dep= Hospital Anxiety and Depression Scale - depression subscale. ${ }^{*} \mathrm{p}<.05 ; * * \mathrm{p}<.01 ; * * * \mathrm{p}<.001$ 


\subsection{The influence of DIF and negative affect on drive for thinness}

In order to establish if negative affect mediated the effect of DIF on drive for thinness we conducted a regression with DIF score (TAS-20) as the predictor variable, DFT subscale score as the dependent variable, and negative affect as the mediator. The paths from this model are illustrated in Figure 2 and the corresponding coefficients and 95\% CI are presented in Table 3.

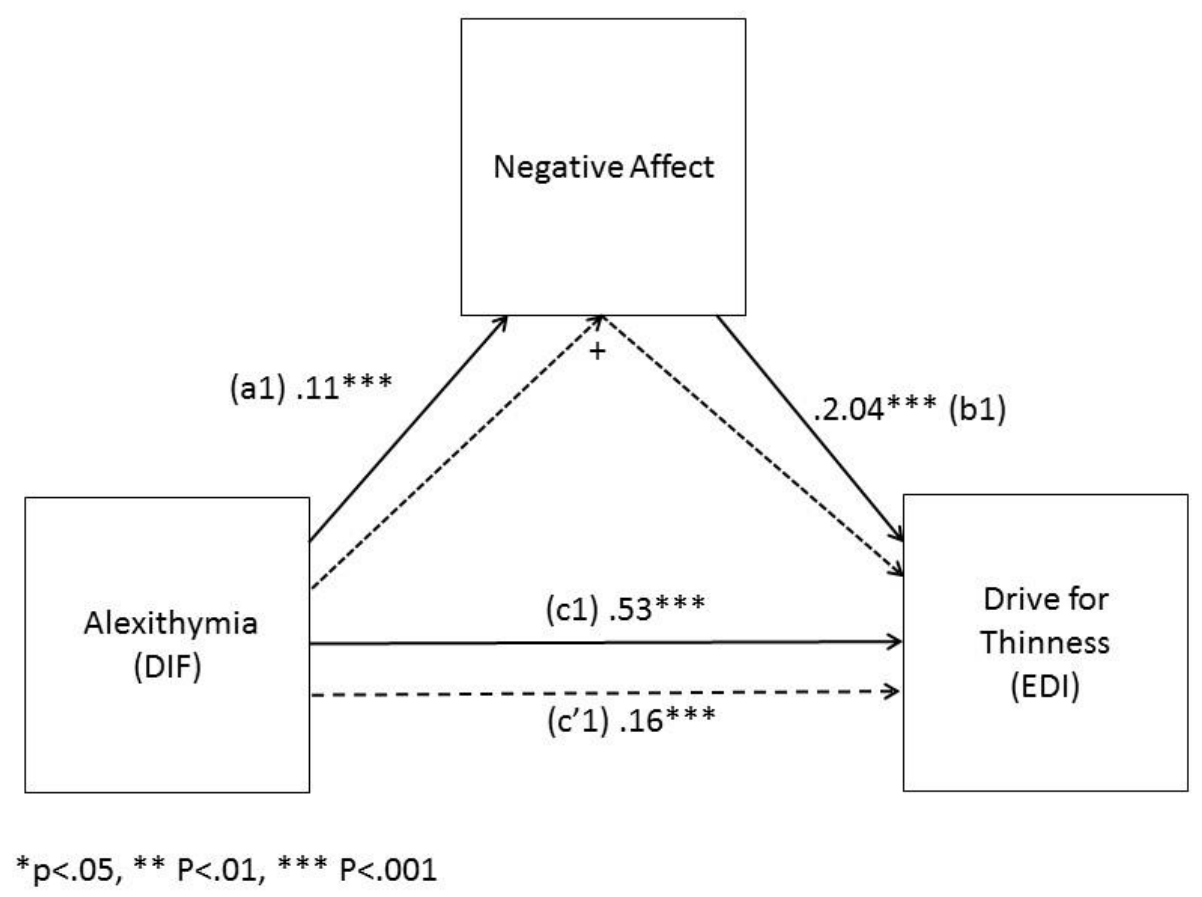

Figure 2. Direct and indirect effects of alexithymia (DIF) on drive-for thinness via the mediator (negative affect)

The path (a1) from DIF to the mediator (negative affect) was significant, as was the path (b1) from the mediator to the dependent variable (drive for thinness score). The total effect of DIF on drive for thinness (c1) was significant, as was the direct effect (c'1), controlling for the influence of negative affect. Furthermore, the indirect effect of DIF (+) via the mediator (negative affect) was also 
significant [95\% CI .10, .33], $\mathrm{p}<.05$. This suggests that DIF influenced drive for thinness both directly and indirectly via negative affect.

Table 3. Path coefficients and $95 \%$ confidence intervals from the mediation analyses of alexithymia (DIF) on Eating Disorder Symptoms (EDI) estimated using PROCESS

\begin{tabular}{|c|c|c|c|c|}
\hline & Path estimates & Coefficient (SE) & LLCI & ULCI \\
\hline \multirow[t]{4}{*}{ Drive for Thinness [1] } & a1 & $.11(.25)^{* * *}$ & .09 & .12 \\
\hline & b1 & $2.04(.48)^{* * *}$ & 1.09 & 3.0 \\
\hline & c1 & $.53(.06)^{* * *}$ & .41 & .66 \\
\hline & $c^{\prime} 1$ & $.32(.08)^{*}$ & .16 & .48 \\
\hline \multirow[t]{4}{*}{ Bulimia [2] } & a2 & $.11(.25)^{* * *}$ & .09 & .12 \\
\hline & b2 & $1.4(.27)^{* * *}$ & .89 & 1.96 \\
\hline & c2 & $.25(.04)^{* * *}$ & .18 & .32 \\
\hline & $c^{\prime} 2$ & $.10(.05)^{*}$ & .01 & .19 \\
\hline \multirow[t]{4}{*}{ Body Dissatisfaction [3] } & a3 & $.11(.25)^{* * *}$ & .09 & .12 \\
\hline & b3 & $3.56(.71)^{* * *}$ & 2.17 & 5.0 \\
\hline & c3 & $.55(.10)^{* * *}$ & .36 & .74 \\
\hline & $c^{\prime} 3$ & $.17(.12)^{\mathrm{NS}}$ & -.07 & .40 \\
\hline Indirect effects & Path & Effect (SE) & LLCI & ULCI \\
\hline [1] & + & $.21(.06)^{*}$ & .10 & .33 \\
\hline [2] & + & $.26(.07)^{*}$ & .13 & .39 \\
\hline [3] & + & $.26(.06)^{*}$ & .15 & .37 \\
\hline
\end{tabular}

Note. LLCI $=95 \%$ lower-limit confidence interval; ULCI $=95 \%$ upper-limit confidence interval. $a=$ path from alexithymia to mediator (negative affect), $b=$ path from the mediator to eating disorder symptoms, $c=$ total effect of alexithymia on eating disorder symptoms, c'=direct effect of alexithymia on eating disorder symptoms, 
controlling for the effect of the mediator, $+=$ the indirect effect of alexithymia on eating disorder symptoms via the mediator (negative affect). Significance levels: $* \mathrm{p}<.05, * * * \mathrm{p}<.001$.

\subsection{The influence of DIF and negative affect on bulimia score}

In order to determine if negative affect mediated the effect of DIF on symptoms of bulimia we conducted a further regression with DIF scores as the predictor variable, negative affect as the mediator and scores on the bulimia subscale of the EDI as the dependent variable. The paths from this model are illustrated in Figure 3 and the corresponding coefficients and 95\% CI are presented in Table 3.

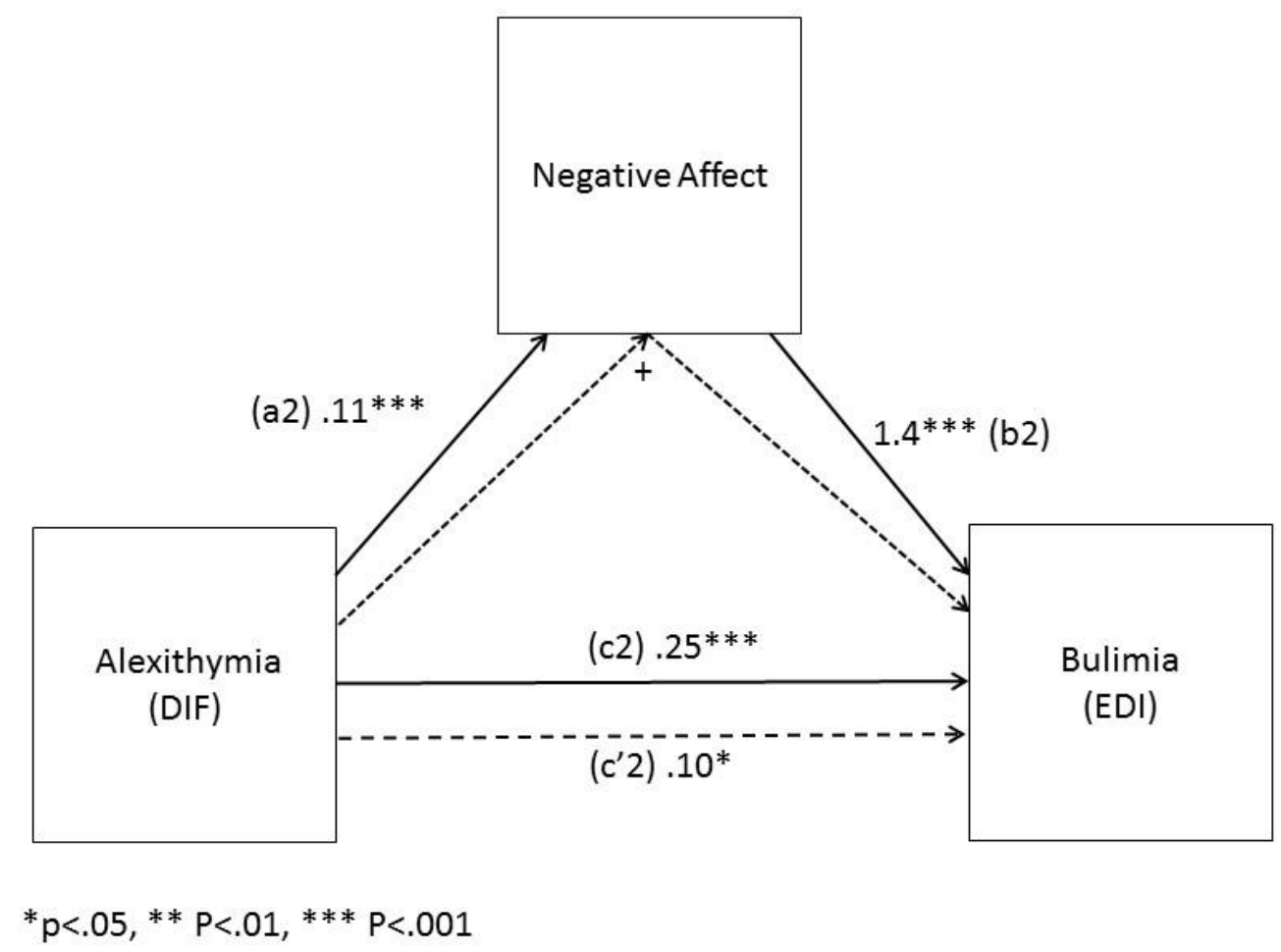

Figure 3. Direct and indirect effects of alexithymia (DIF) on bulimia via the mediator (negative affect)

The path (a2) from DIF to the mediator (negative affect) was significant, as was the path (b2) from the mediator to the dependent variable (bulimia score). The total effect of DIF on 
bulimia (c2) was significant, as was the direct effect (c'2), controlling for the influence of negative affect. Furthermore, the indirect effect of DIF (+) via the mediator (negative affect) was also significant $[95 \%$ CI .13, .39], $\mathrm{p}<.05$. This suggests that DIF influenced bulimia both directly and indirectly via negative affect.

\subsection{The influence of DIF and negative affect on body dissatisfaction}

In order to establish if negative affect mediated the effect of DIF on body dissatisfaction we conducted a regression with DIF score (TAS-20) as the predictor variable, body dissatisfaction subscale score (EDI) as the dependent variable, and negative affect as the mediator. The paths from this model are illustrated in Figure 4 and the corresponding coefficients and 95\% CI are presented in Table 3.

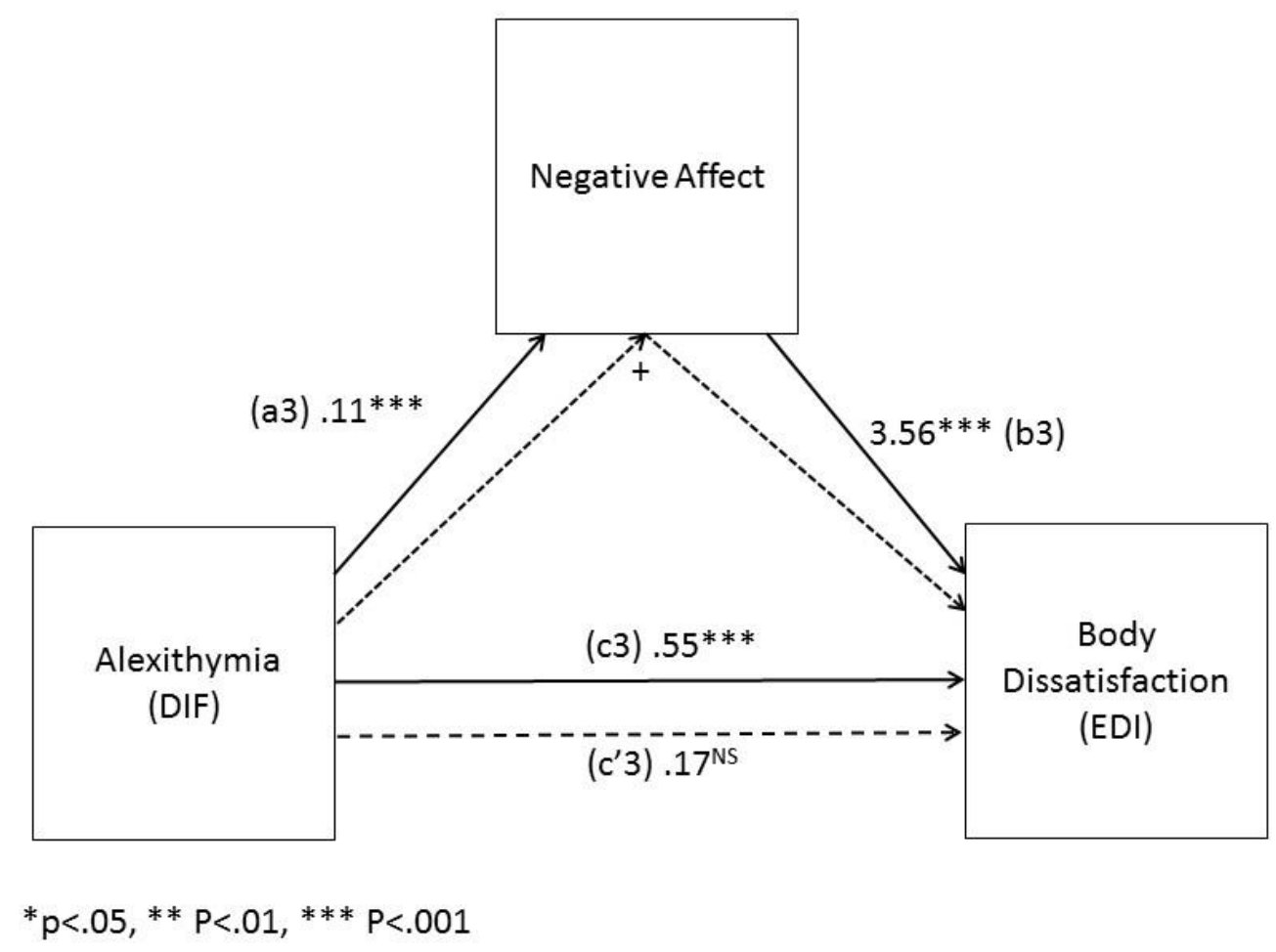

Figure 4. Direct and indirect effects of alexithymia (DIF) on body dissatisfaction via the mediator (negative affect) 
The path (a3) from DIF to the mediator (negative affect) was significant, as was the path (b3) from the mediator to the dependent variable (body dissatisfaction score). The total effect of DIF on body dissatisfaction (c3) was significant, but there was no direct effect of DIF (c'3), once the influence of negative affect had been controlled for. The indirect effect of DIF (+) via the mediator (negative affect) was significant [95\% CI .15, .37], $\mathrm{p}<.05$. This suggests that DIF only influenced body dissatisfaction indirectly via negative affect.

\subsection{The influence of DDF and negative affect on drive for thinness}

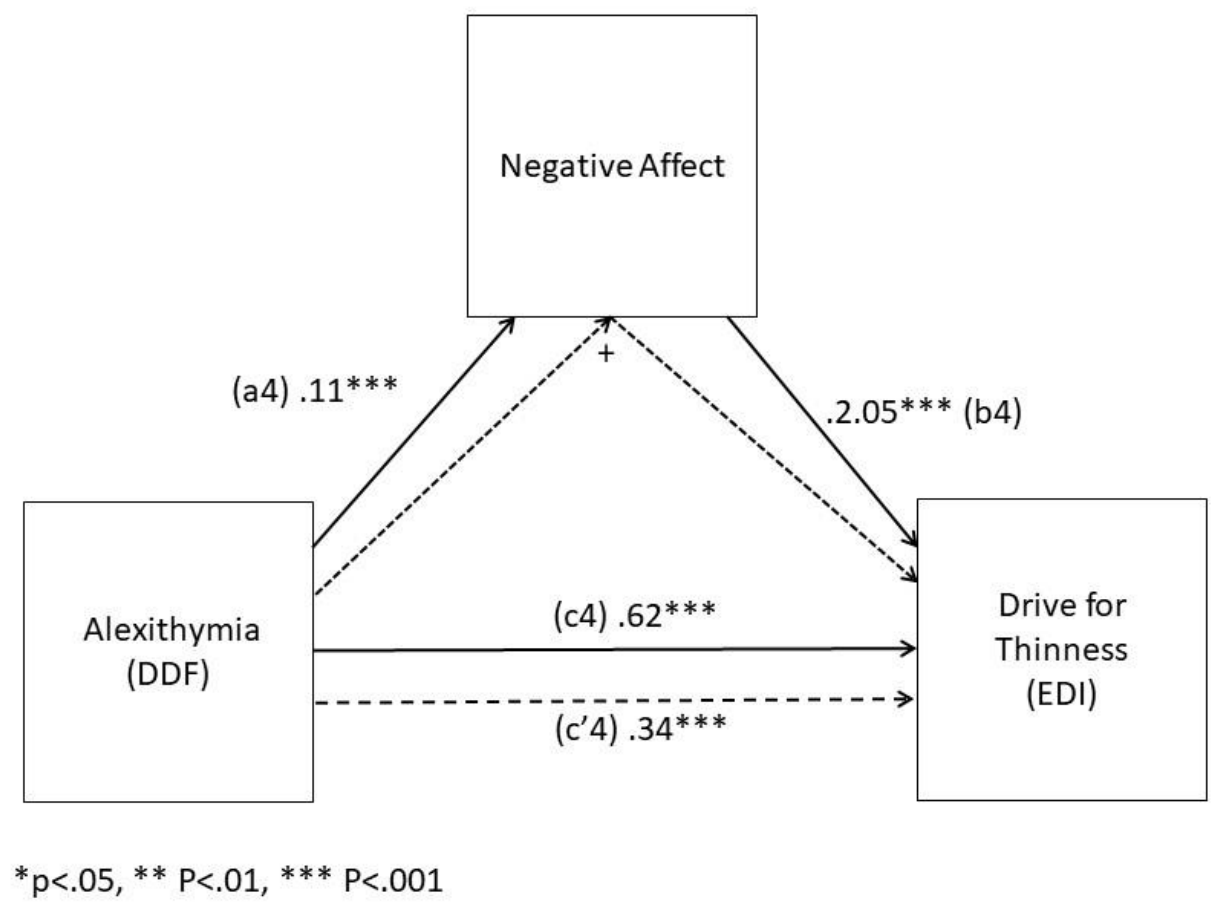

Figure 5. Direct and indirect effects of alexithymia (DDF) on drive-for thinness via the mediator (negative affect)

In order to establish if negative affect mediated the effect of DDF on drive for thinness we conducted a regression with DDF score (TAS-20) as the predictor variable, DFT subscale score as the dependent variable, and negative affect as the mediator. The paths from this 
model are illustrated in Figure 5 and the corresponding coefficients and 95\% CI are presented in Table 4.

Table 4. Path coefficients and $95 \%$ confidence intervals from the mediation analyses of alexithymia (DDF) on Eating Disorder Symptoms (EDI) estimated using PROCESS

\begin{tabular}{|c|c|c|c|c|}
\hline & Path estimates & Coefficient (SE) & LLCI & ULCI \\
\hline \multirow[t]{4}{*}{ Drive for Thinness [4] } & a4 & $.11(.01)^{* * *}$ & .08 & .14 \\
\hline & b4 & $2.05(.43)^{* * *}$ & 1.66 & 3.36 \\
\hline & $\mathrm{c} 4$ & $.62(.09)^{* * *}$ & .44 & .79 \\
\hline & $c^{\prime} 4$ & $.34(.10)^{* * *}$ & .15 & .53 \\
\hline \multirow[t]{4}{*}{ Bulimia [5] } & a5 & $.11(.01)^{* * * *}$ & .08 & .14 \\
\hline & b5 & $1.67(.24)^{* * *}$ & 1.20 & 2.15 \\
\hline & $\mathrm{c5}$ & $.24(.05)^{* * *}$ & .14 & .34 \\
\hline & $c^{\prime} 5$ & $.05(.05)^{\mathrm{NS}}$ & -.05 & .16 \\
\hline \multirow[t]{4}{*}{ Body Dissatisfaction [6] } & a6 & $.11(.01)^{* * *}$ & .08 & .14 \\
\hline & b6 & $3.37(.62)^{* * *}$ & 2.16 & 4.59 \\
\hline & c6 & $.75(.13) * * *$ & .50 & 1.0 \\
\hline & $c^{\prime} 6$ & $.38(.14)^{* *}$ & .11 & .62 \\
\hline Indirect effects & Path & Effect (SE) & LLCI & ULCI \\
\hline [4] & + & $.27(.07)^{*}$ & .15 & .41 \\
\hline [5] & + & $.18(.05)^{*}$ & .10 & .28 \\
\hline [6] & + & $.37(.09)^{*}$ & .22 & .55 \\
\hline
\end{tabular}

Note. LLCI $=95 \%$ lower-limit confidence interval; ULCI $=95 \%$ upper-limit confidence interval. $a=$ path from alexithymia to mediator (negative affect), $b=$ path from the mediator to eating disorder symptoms, $c=$ total effect of alexithymia on eating disorder symptoms, $c^{\prime}=$ direct effect of alexithymia on eating disorder symptoms, 
controlling for the effect of the mediator, $+=$ the indirect effect of alexithymia on eating disorder symptoms via the mediator (negative affect). Significance levels: $* \mathrm{p}<.05, * * \mathrm{p}<.01 * * * \mathrm{p}<.001$.

The path (a4) from alexithymia (DIF) to the mediator (negative affect) was significant, as was the path (b4) from the mediator to the dependent variable (drive for thinness score). The total effect of alexithymia on drive for thinness (c4) was significant, as was the direct effect (c'4), controlling for the influence of negative affect. Furthermore, the indirect effect of DDF (+) via the mediator (negative affect) was also significant [95\% CI .15, .41], p<.05. This suggests that DDF influenced drive for thinness directly, and indirectly via negative affect.

3.7. The influence of DDF and negative affect on bulimia score

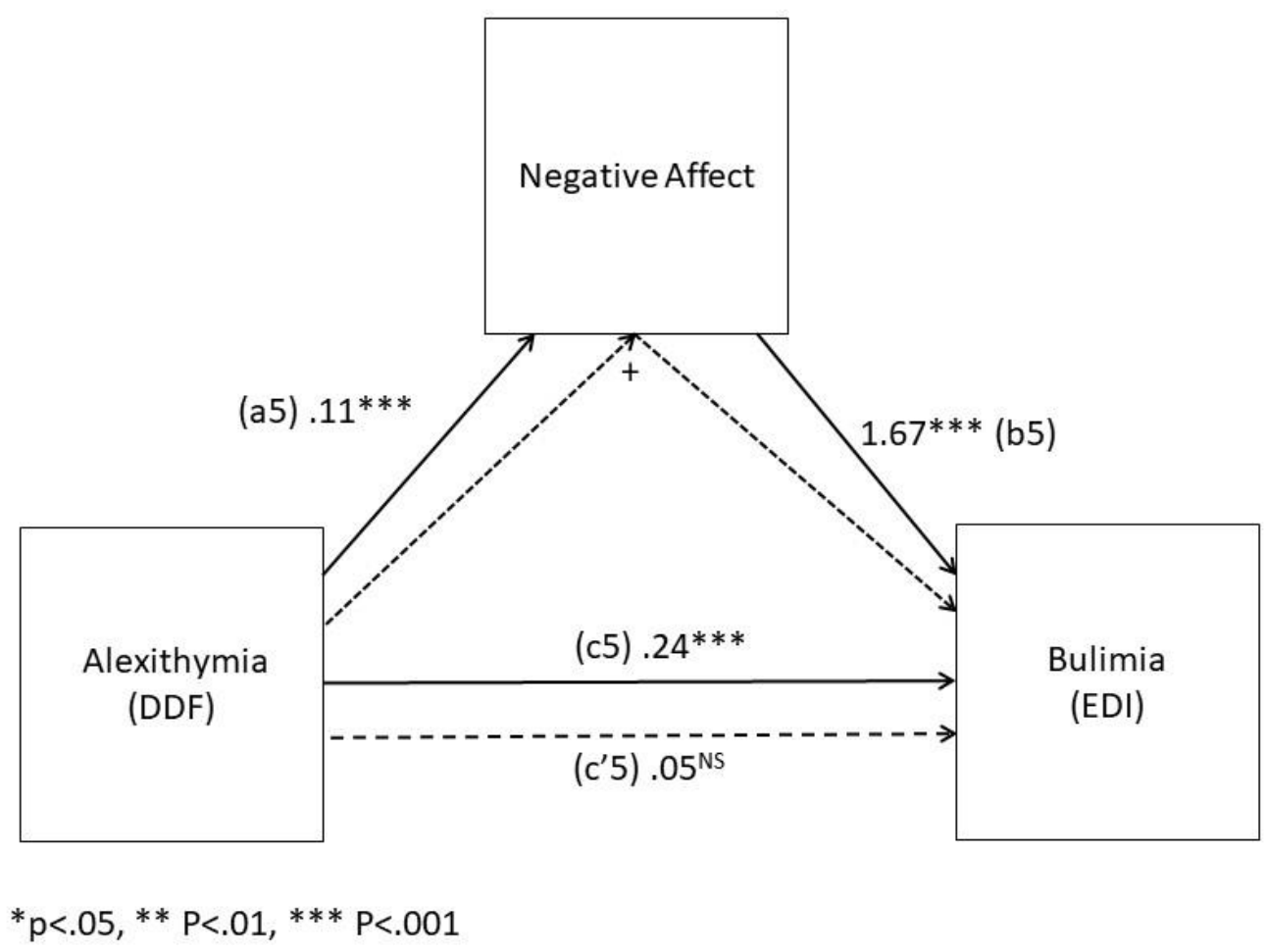

Figure 6. Direct and indirect effects of alexithymia (DDF) on bulimia via the mediator (negative affect) 
In order to determine if negative affect mediated the effect of DDF on symptoms of bulimia we conducted a further regression with DDF scores as the predictor variable, negative affect as the mediator and scores on the bulimia subscale of the EDI as the dependent variable. The paths from this model are illustrated in Figure 6 and the corresponding coefficients and 95\% CI are presented in Table 4.

The path (a5) from DDF to the mediator (negative affect) was significant, as was the path (b5) from the mediator to the dependent variable (bulimia score). The total effect of DDF on bulimia (c5) was significant. However, the direct effect (c'5), controlling for negative affect, was not significant, but the indirect effect of DDF (+) via the mediator (negative affect) was significant $[95 \%$ CI .10, .28], $\mathrm{p}<.05$. This suggests that DDF influenced bulimia only indirectly via negative affect.

\subsection{The influence of DDF and negative affect on body dissatisfaction}

In order to establish if negative affect mediated the effect of DDF on body dissatisfaction we conducted a final regression with DDF score (TAS-20) as the predictor variable, body dissatisfaction subscale score (EDI) as the dependent variable, and negative affect as the mediator. The paths from this model are illustrated in Figure 7 and the corresponding coefficients and 95\% CI are presented in Table 4.

The path (a6) from DDF to the mediator (negative affect) was significant, as was the path (b6) from the mediator to the dependent variable (drive for thinness score). The total effect of DDF on drive for thinness (c6) was significant as was the direct effect of DDF. The indirect effect of DDF (+) via the mediator (negative affect) was also significant [95\% CI .12, .55], $\mathrm{p}<.05$. This suggests that DDF influenced body dissatisfaction directly, and indirectly via negative affect. 


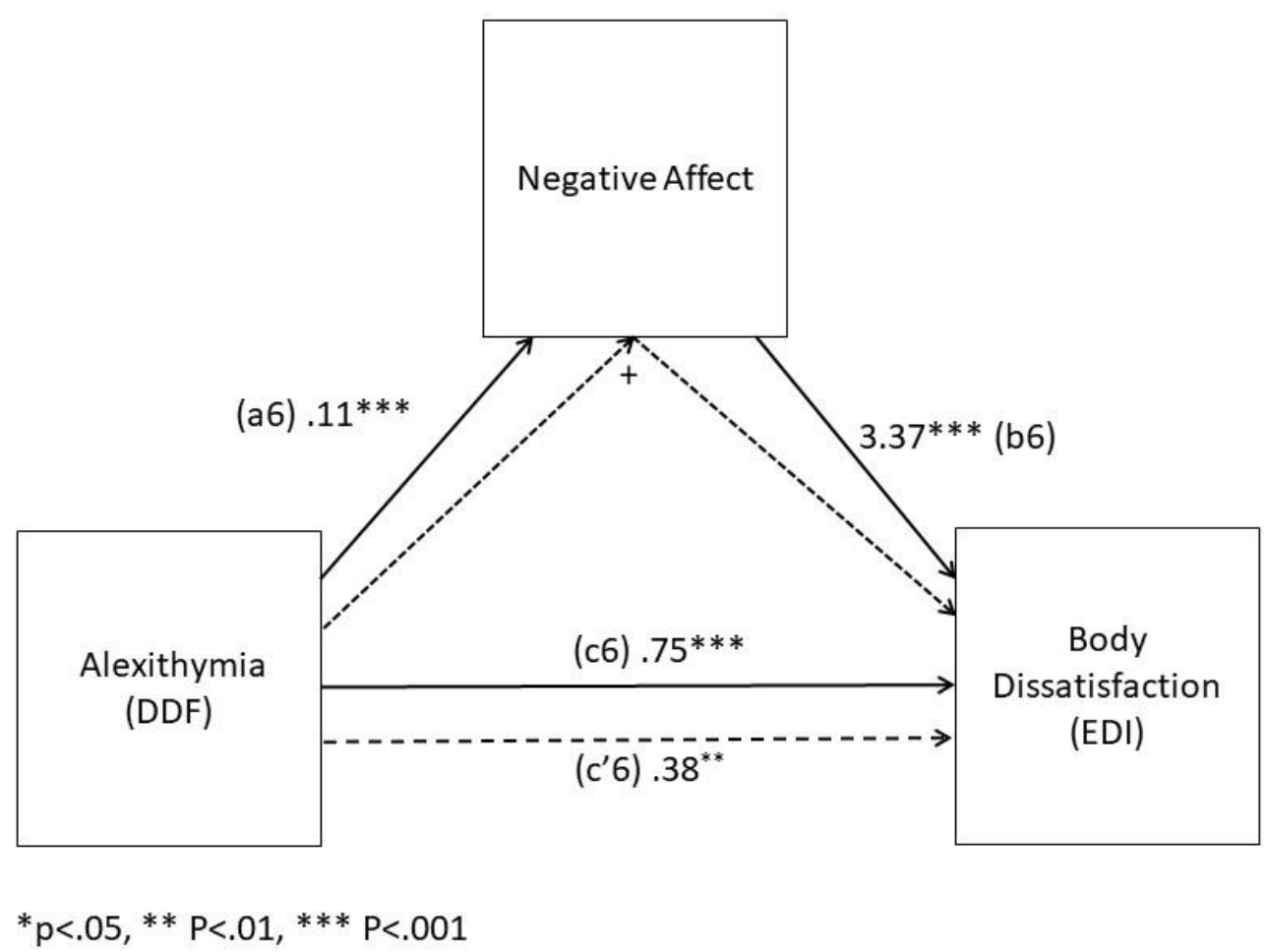

Figure 7. Direct and indirect effects of alexithymia (DDF) on body dissatisfaction via the mediator (negative affect)

\section{Discussion}

The aim of the current study was to determine if negative affect mediated the influence of alexithymia on disordered eating in a non-clinical female sample. As predicted, negative affect mediated the effect of the alexithymia facets difficulty identifying feelings (DIF) and difficulty describing feelings (DDF) on all symptoms of disordered eating (drive for thinness, bulimia, and body dissatisfaction). This suggests that alexithymia influences disordered eating indirectly via negative mood. This is consistent with the findings in clinically diagnosed patients with anorexia nervosa (Torres et al., 2015). Furthermore, as expected, the pattern of mediation varied as a function of alexithymia facet. In line with Torres and colleagues, direct pathways between DIF and drive for thinness and between DIF and bulimia 
were observed in the current study. However, the expected direct pathway between DIF and body dissatisfaction was not significant. There was no direct effect of DDF on bulimia, as expected. Nevertheless, direct pathways were evident between DDF and drive for thinness and between DDF and body dissatisfaction. Taken together, our findings suggest that two facets of alexithymia (DIF and DDF) influence disordered eating directly and indirectly via negative affect, although the direct effects are dependent on the type of eating disorder symptoms.

Torres et al (2015) proposed that depression mediated the effect of alexithymia (DIF and DDF) on disordered eating by increasing levels of alexithymia, which in turn led to disordered eating. However, we question the validity of that explanation, both conceptually and theoretically. Conceptually, it seems counterintuitive to expect that the mediator would influence the DV by changing the levels of the predictor variable. Theoretically, although levels of alexithymia do increase during episodes of depression and eating disorders, they remain high in recovered patients relative to controls (Courty et al., 2015; Gunther et al., 2016; Luminet et al., 2001; Tchanturia et al., 2012). This supports the notion that alexithymia is a stable characteristic of individuals who are prone to depression and disordered eating rather than merely a state phenomenon associated with psychopathology. From this perspective, we suggest that more valid explanation is that alexithymia indirectly influences disordered eating by increasing levels of negative affect, which then leads to disordered eating (Jacobi et al., 2011, Stice et al., 2011; 2017). Consistent with this line of thought, Ivanova et al. (2015) explained their finding that negative affect mediated the effect of interpersonal problems on binge eating by suggesting that interpersonal problems led to higher negative affect, which in turn led to increased tendency to binge eating. It is worth noting that there is consistent evidence linking alexithymia with interpersonal problems (Spitzer et al. 2005; Vanheule, Desmet, Meganck \& Bogaert, 2007; Zareia \& Besharat, 
2010). Thus, alexithymia might provide an additional explanation for the findings of Ivanova et al (2015). Furthermore, it is plausible that poor interpersonal functioning might represent a link between alexithymia and negative affect in the explanatory model for disordered eating. Another factor that could plausibly link alexithymia, negative affect and disordered eating is emotion regulation. Poor emotion regulation has been implicated in depression (Joormann \& Stanton, 2016), anxiety (Cisler \& Olatunji, 2012) and disordered eating (Harrison et al., 2010; Oldershaw et al., 2015; Svaldi et al., 2012). However, poor emotion regulation has also been linked to alexithymia (Dubey, Pandey, \& Mishra, 2010; Taylor, 2000). Thus, given the conception of alexithymia as a trait vulnerability factor for psychopathology, it is plausible that poor emotion regulation might represent a pathway via which alexithymia might lead to psychological distress and disordered eating. These proposals need to be examined in future studies.

Regarding the direct effect of DIF on drive for thinness and bulimia, these findings are consistent with previous studies that have observed relationships between poor emotional awareness and a preoccupation with weight and tendency towards restrained eating (Legenbauer, Vocks \& Rüddel, 2008; Sim \& Zeman, 2006; Strodi \& Wylie, 2020) and bulimic symptoms (Benau, Wiatrowski Timko, 2020; Quinton \& Wagner, 2005; Sim \& Zeman, 2006). Individuals who have difficulties identifying their feelings would find it more difficult to regulate their emotional experiences using adaptive strategies, such as reappraisal (Venta, Hart \& Sharp, 2012), and may be more likely to use maladaptive methods, such as suppression. Ineffective emotion regulation may lead these individuals to use food as a method of distracting from their mood. In line with this notion, Taut, Renner and Baban (2012) demonstrated that food was used a secondary coping mechanism when emotion recognition strategies were unsuccessful. Further, they showed that avoidance of emotion (suppression) was linked to the initiation of food intake. Similarly, impaired emotion 
regulation has been linked to dietary restraint (van Durme, Caroline Braet, \& Goossens, 2015).

Regarding the direct effect of DDF on drive for thinness and body dissatisfaction, these findings are consistent with previous studies reporting links between DDF and restrained eating (Strodl \& Wylie, 2020) and body dissatisfaction (De Berardis et al., 2009; Fenwick \& Sullivan, 2011; Hund \& Espelage, 2006). However, they are inconsistent with other studies (Quinton \& Wagner, 2005), which have reported no evidence of links between DDF and drive for thinness and body dissatisfaction. One explanation for how DDF might influence disordered eating is via reduced emotional expression. For example, Luminet, Rimé, Bagby and Taylor (2004) reported that DDF scores were associated with the use of fewer emotion words when describing an emotional event. Furthermore, Paez et al (1999) reported that DDF was linked to inhibited emotional expression and Quinton and Wagner (2005) demonstrated that DDF was associated with lower emotional intimacy. It is notable that poor emotional expression has been implicated in body dissatisfaction (Ioannou \& Fox, 2009; Hyaki, Friedman \& Brownell, 2002) and drive for thinness (Ioannou \& Fox, 2009). Thus, if individuals with high DDF have problems expressing their emotions to others it is plausible that this may put them at risk of developing disordered eating. This could be examined in future studies.

As the current sample consists of female undergraduate students it limits the generalisability of the findings, most notably to males, but potentially to the general population. However, the findings in our non-clinical sample are consistent with those reported in a sample of patients with clinically diagnosed anorexia (Torres et al., 2015), which suggests the current findings are likely to be generalisable to females with a spectrum of disordered eating symptoms. As the current study and Torres et al. (2015) both used the TAS-20 to measure alexithymia, the findings might not generalise to other measures of alexithymia (e.g. Bermond-Vorst 
Alexithymia Questionnaire; BVAQ). However, scores on these measures tend to be significantly correlated. For example, Zech et al. (1999) reported a significant positive relationship (total scores $\mathrm{r}=.62$ ) between to two measures, with the subscales measuring difficulty identifying and describing feelings correlating more strongly ( $\mathrm{r}=.7$ and $\mathrm{r}=.8$ respectively). This suggests that similar findings would be observed if the BVAQ was used in place of the TAS-20. Future work is needed to examine if alexithymia predicts disordered eating in males and if this relationship is mediated by negative affect.

In sum, our findings confirm that negative affect mediates the effect of alexithymia (DIF and DDF) on disordered eating (drive-for-thinness, bulimia and body dissatisfaction) but importantly, having controlled for the effect of negative affect, there is still evidence of direct relationships between these two facets of alexithymia and disordered eating. Although the current findings are cross-sectional and correlational and, thus, cannot provide evidence of the direction of causation, considering the evidence that alexithymia is a potential trait risk factor for disordered eating (Courty et al., 2015; Tchanturia et al., 2012), targeted interventions to address deficits in recognising and describing ones feelings could potentially be beneficial for individuals who are at risk of developing disordered eating. 
Acknowledgements: none

Data Sharing Statement: The data analysed and reported in this manuscript can be found at doi: 10.17632/tfbh8vsrkz.2

Conflicts of Interest: Neither author has any conflict of interest to declare

Funding: This research did not receive any specific grant from funding agencies in the public, commercial, or not-for-profit sectors 


\section{References}

Abbate-Daga, G., Quaranta, M., Marzola, E., Amianto, F., \& Fassino, S. (2015). The relationship between alexithymia and intolerance of uncertainty in anorexia nervosa. Psychopathology, 48(3), 202208. https://doi.org/10.1159/000381587

Andrews, B., \& Wilding, J. M. (2004). The relation of depression and anxiety to life-stress and achievement in students. British Journal of Psychology, 95(4), 509-521. https://doi.org/10.1348/0007126042369802

Alpaslan, A. H., Soylu, N., Kadriye, A. V. C. I., Coşkun, K. Ş., Kocak, U., \& Taş, H. U. (2015).

Disordered eating attitudes, alexithymia and suicide probability among Turkish high school girls. Psychiatry Research, 226(1), 224-229. https://doi.org/10.1016/j.psychres.2014.12.052

Bagby, R. M., Parker, J. D. A., \& Taylor, G. J. (1994a). The 20-Item Toronto-Alexithymia-Scale. 1. Item selection and cross-validation of the factor structure. Journal of Psychosomatic Research, 38(2), $3-32$.

Bagby, R. M., Taylor, G. J., \& Parker, J. D. A. (1994b). The 20-Item Toronto-Alexithymia-Scale. 2. Convergent, discriminant, and concurrent validity. Journal of Psychosomatic Research, 38(3), 3-40.

Beales, D. L., \& Dolton, R. (2000). Eating disordered patients: personality, alexithymia, and implications for primary care. British Journal of General Practice, 50(450), 21-26.

Benau, E. M., Wiatrowski, R., \& Timko, C. A. (2020). Difficulties in emotion regulation, alexithymia, and social phobia are associated with disordered eating in male and female undergraduate athletes. Frontiers in Psychology, 11, 1646. https://doi.org/10.3389/fpsyg.2020.01646

Bjelland, I., Dahl, A. A., Haug, T. T., \& Neckelmann, D. (2002). The validity of the Hospital Anxiety and Depression Scale: an updated literature review. Journal of Psychosomatic Research, 52(2), 69-77. https://doi.org/10.1016/S0022-3999(01)00296-3 
Brewin, N., Baggott, J., Dugard, P., \& Arcelus, J. (2014). Clinical normative data for eating disorder examination questionnaire and eating disorder inventory for DSM-5 feeding and eating disorder classifications: A retrospective study of patients formerly diagnosed via DSM-IV. European Eating Disorders Review, 22(4), 299-305. https://doi.org/10.1002/erv.2301

Carano, A., De Berardis, D., Campanella, D., Serroni, N., Ferri, F., Di Iorio, G., ... \& Moschetta, F. S. (2012). Alexithymia and suicide ideation in a sample of patients with binge eating disorder. Journal of Psychiatric Practice, 18(1), 5-11. doi: 10.1097/01.pra.0000410982.08229.99

Cisler, J. M., \& Olatunji, B. O. (2012). Emotion regulation and anxiety disorders. Current Psychiatry Reports, 14(3), 182-187. DOI 10.1007/s11920-012-0262-2

Clyne, C., Latner, J. D., Gleaves, D. H., \& Blampied, N. M. (2010). Treatment of emotional dysregulation in full syndrome and subthreshold binge eating disorder. Eating Disorders, 18(5), 408424. https://doi.org/10.1080/10640266.2010.511930

Conrad, R., Wegener, I., Imbierowicz, K., Liedtke, R., \& Geiser, F. (2009). Alexithymia, temperament and character as predictors of psychopathology in patients with major depression. Psychiatry Research, 165(1-2), 137-144. https://doi.org/10.1016/j.psychres.2007.10.013 Corcos, M., Guilbaud, O., Speranza, M., Paterniti, S., Loas, G., Stephan, P., \& Jeammet, P. (2000). Alexithymia and depression in eating disorders. Psychiatry Research, 93(3), 263-266. https://doi.org/10.1016/S0165-1781(00)00109-8

Courty, A., Godart, N., Lalanne, C., \& Berthoz, S. (2015). Alexithymia, a compounding factor for eating and social avoidance symptoms in anorexia nervosa. Comprehensive Psychiatry, 56, 217-228. https://doi.org/10.1016/j.comppsych.2014.09.011

De Berardis, D., Carano, A., Gambi, F., Campanella, D., Giannetti, P., Ceci, A., ... \& Di Matteo, D. (2007). Alexithymia and its relationships with body checking and body image in a non-clinical female sample. Eating Behaviors, 8(3), 296-304. https://doi.org/10.1016/j.eatbeh.2006.11.005 
De Berardis, D., Serroni, N., Campanella, D., Carano, A., Gambi, F., Valchera, A., ... \& Cotellessa, C. (2009). Alexithymia and its relationships with dissociative experiences, body dissatisfaction and eating disturbances in a non-clinical female sample. Cognitive Therapy and Research, 33(5), 471-479. DOI 10.1007/s10608-009-9247-9

Dubey, A., Pandey, R. \& Mishra, K. (2010). Role of emotion regulation difficulties and positive/negative affectivity in explaining alexithymia-health relationship: An overview. Indian Journal of Social Science Researches; 7, 20 - 31.

Eizaguirre, A. E., de Cabezón, A. O. S., de Alda, I. O., Olariaga, L. J., \& Juaniz, M. (2004). Alexithymia and its relationships with anxiety and depression in eating disorders. Personality and Individual Differences, 36(2), 321-331. https://doi.org/10.1016/S0191-8869(03)00099-0

Fenwick, A. S., \& Sullivan, K. A. (2011). Potential link between body dysmorphic disorder symptoms and alexithymia in an eating-disordered treatment-seeking sample. Psychiatry Research, 189(2), 299304. https://doi.org/10.1016/j.psychres.2011.07.011

Franz, M., Popp, K., Schaefer, R., Sitte, W., Schneider, C., Hardt, J., ... \& Braehler, E. (2008). Alexithymia in the German general population. Social Psychiatry and Psychiatric Epidemiology, 43(1), 54-62. DOI 10.1007/s00127-007-0265-1

Garner, D. M. (1991). Eating Disorders Inventory - 2, Professional Manual. Odessa, FL: Psychological Assessment Resources.

Gilanifar, M., \& Delavar, M. A. (2016). Alexithymia in pregnant women: its relationship with depression. ASEAN Journal of Psychiatry, 17(1).

Grabe, H. J., Spitzer, C., \& Freyberger, H. J. (2004). Alexithymia and personality in relation to dimensions of psychopathology. American Journal of Psychiatry, 161(7), 1299-1301. https://doi.org/10.1176/appi.ajp.161.7.1299 
Günther, V., Rufer, M., Kersting, A., \& Suslow, T. (2016). Predicting symptoms in major depression after inpatient treatment: the role of alexithymia. Nordic Journal of Psychiatry, 70(5), 392-398.

https://doi.org/10.3109/08039488.2016.1146796

Harrison, A., Sullivan, S., Tchanturia, K., \& Treasure, J. (2010). Emotional functioning in eating disorders: attentional bias, emotion recognition and emotion regulation. Psychological Medicine, 40(11), 1887. doi:10.1017/S0033291710000036

Hayes, A. F. (2017). Introduction to mediation, moderation, and conditional process analysis: A regression-based approach. Guilford publications.

Honkalampi, K., Hintikka, J., Tanskanen, A., Lehtonen, J., \& Viinamäki, H. (2000). Depression is strongly associated with alexithymia in the general population. Journal of Psychosomatic Research, 48(1), 99-104. https://doi.org/10.1016/S0022-3999(99)00083-5

Honkalampi, K., De Berardis, D., Vellante, F., \& Viinamäki, H. (2018). Relations between alexithymia and depressive and anxiety disorders and personality. In O. Luminet, R. M. Bagby, \& G. J. Taylor (Eds.), Alexithymia: Advances in research, theory, and clinical practice (p. 142-157). Cambridge University Press. https://doi.org/10.1017/9781108241595.011

Hund, A. R., \& Espelage, D. L. (2006). Childhood emotional abuse and disordered eating among undergraduate females: Mediating influence of alexithymia and distress. Child Abuse \& Neglect, 30(4), 393-407. https://doi.org/10.1016/j.chiabu.2005.11.003

Hayaki, J., Friedman, M. A., \& Brownell, K. D. (2002). Emotional expression and body dissatisfaction. International Journal of Eating Disorders, 31(1), 57-62. https://doi.org/10.1002/eat.1111 Ioannou, K., \& Fox, J. R. (2009). Perception of threat from emotions and its role in poor emotional expression within eating pathology. Clinical Psychology \& Psychotherapy: An International Journal of Theory \& Practice, 16(4), 336-347. https://doi.org/10.1002/cpp.632 
Ivanova, I. V., Tasca, G. A., Hammond, N., Balfour, L., Ritchie, K., Koszycki, D., \& Bissada, H. (2015). Negative affect mediates the relationship between interpersonal problems and binge-eating disorder symptoms and psychopathology in a clinical sample: A test of the interpersonal model. European Eating Disorders Review, 23(2), 133-138. https://doi.org/10.1002/erv.2344

Jacobi, C., Fittig, E., Bryson, S. W., Wilfley, D., Kraemer, H. C., \& Taylorc, C. B. (2011). Who is really at risk? Identifying risk factors for subthreshold and full syndrome eating disorders in a highrisk sample. Psychological Medicine, 41(9), 1939. 10.1017/S0033291710002631

Joormann, J., \& Stanton, C. H. (2016). Examining emotion regulation in depression: A review and future directions. Behaviour Research and Therapy, 86, 35-49.

https://doi.org/10.1016/j.brat.2016.07.007

Kojima, M., Hayano, J., Tokudome, S., Suzuki, S., Ibuki, K., Tomizawa, H., ... \& Furukawa, T. A. (2007). Independent associations of alexithymia and social support with depression in hemodialysis patients. Journal of Psychosomatic Research, 63(4), 349-356.

https://doi.org/10.1016/j.jpsychores.2007.04.002

Legenbauer, T., Vocks, S., \& Rüddel, H. (2008). Emotion recognition, emotional awareness and cognitive bias in individuals with bulimia nervosa. Journal of Clinical Psychology, 64(6), 687-702. https://doi.org/10.1002/jiclp.20483

Leweke, F., Leichsenring, F., Kruse, J., \& Hermes, S. (2012). Is alexithymia associated with specific mental disorders. Psychopathology, 45(1), 22-28. https://doi.org/10.1159/000325170

Limbert, C. (2004). The Eating Disorder Inventory: A test of the factor structure and internal consistency in a nonclinical sample. Health Care for Women International, 25(2), 165-178. https://doi.org/10.1080/07399330490267486

Luca, M., Luca, A., \& Calandra, C. (2013). Psychomotor retardation and externally oriented thinking in major depression. Neuropsychiatric Disease and Treatment, 9, 759. 10.2147/NDT.S44650 
Luminet, O., Bagby, R. M., \& Taylor, G. J. (2001). An evaluation of the absolute and relative stability of alexithymia in patients with major depression. Psychotherapy and Psychosomatics, 70(5), 254-260. https://doi.org/10.1159/000056263

Luminet, O., Rimé, B., Bagby, R. M., \& Taylor, G. (2004). A multimodal investigation of emotional responding in alexithymia. Cognition and Emotion, 18(6), 741-766.

https://doi.org/10.1080/02699930341000275

Mattila, A. K., Salminen, J. K., Nummi, T., \& Joukamaa, M. (2006). Age is strongly associated with alexithymia in the general population. Journal of Psychosomatic Research, 61(5), 629-635. https://doi.org/10.1016/j.jpsychores.2006.04.013

Morie, K. P., \& Ridout, N. (2018). Alexithymia and maladaptive regulatory behaviors in substance use disorders and eating disorders. In O. Luminet, R. M. Bagby, \& G. J. Taylor (Eds.), Alexithymia: Advances in research, theory, and clinical practice, 158-174.

Oldershaw, A., Lavender, T., Sallis, H., Stahl, D., \& Schmidt, U. (2015). Emotion generation and regulation in anorexia nervosa: a systematic review and meta-analysis of self-report data. Clinical Psychology Review, 39, 83-95. https://doi.org/10.1016/j.cpr.2015.04.005

Páez, D., Velasco, C., \& González, J. L. (1999). Expressive writing and the role of alexythimia as a dispositional deficit in self-disclosure and psychological health. Journal of Personality and Social Psychology, 77(3), 630. https://doi.org/10.1037/0022-3514.77.3.630

Pinaquy, S., Chabrol, H., Simon, C., Louvet, J. P., \& Barbe, P. (2003). Emotional eating, alexithymia, and binge-eating disorder in obese women. Obesity Research, 11(2), 195-201.

https://doi.org/10.1038/oby.2003.31

Pink, A. E., Lee, M., Price, M., \& Williams, C. (2019). A serial mediation model of the relationship between alexithymia and BMI: The role of negative affect, negative urgency and emotional eating. Appetite, 133, 270-278. https://doi.org/10.1016/j.appet.2018.11.014 
Preacher, K. J., \& Hayes, A. F. (2008). Asymptotic and resampling strategies for assessing and comparing indirect effects in multiple mediator models. Behavior Research Methods, 40(3), 879-891. doi: $10.3758 / B R M .40 .3 .879$

Quinton, S., \& Wagner, H. L. (2005). Alexithymia, ambivalence over emotional expression, and eating attitudes. Personality and Individual Differences, 38(5), 1163-1173.

https://doi.org/10.1016/j.paid.2004.07.013

Ridout, N., Thom, C., \& Wallis, D. J. (2010). Emotion recognition and alexithymia in females with non-clinical disordered eating. Eating Behaviors, 11(1), 1-5.

https://doi.org/10.1016/j.eatbeh.2009.07.008

Ridout, N., Wallis, D. J., Autwal, Y., \& Sellis, J. (2012). The influence of emotional intensity on facial emotion recognition in disordered eating. Appetite, 59(1), 181-186.

https://doi.org/10.1016/j.appet.2012.04.013

[Data set] Ridout, N, Wallis, D.j. (2021), Alexithymia, negative affect and disordered eating, Mendeley Data, V2, doi: 10.17632/tfbh8vsrkz.2

Sharpe, E., Wallis, D. J., \& Ridout, N. (2016). The influence of variations in eating disorder-related symptoms on processing of emotional faces in a non-clinical female sample: An eye-tracking study. Psychiatry Research, 240, 321-327. https://doi.org/10.1016/j.psychres.2016.04.065

Sim, L., \& Zeman, J. (2006). The contribution of emotion regulation to body dissatisfaction and disordered eating in early adolescent girls. Journal of Youth and Adolescence, 35(2), 207-216. DOI: 10.1007/s10964-005-9003-8

Smith, K. E., Mason, T. B., Leonard, R. C., Wetterneck, C. T., Smith, B. E. R., Farrell, N. R., \& Riemann, B. C. (2018). Affective predictors of the severity and change in eating psychopathology in residential eating disorder treatment: The role of social anxiety. Eating Disorders: The Journal of Treatment and Prevention, 26, 66 -78. https://doi.org/10. 1080/10640266.2018.1418314 
Speranza, M., Corcos, M., Loas, G., Stéphan, P., Guilbaud, O., Perez-Diaz, F., ... \& Jeammet, P. (2005). Depressive personality dimensions and alexithymia in eating disorders. Psychiatry Research, 135(2), 153-163. https://doi.org/10.1016/j.psychres.2005.04.001

Speranza, M., Loas, G., Wallier, J., \& Corcos, M. (2007). Predictive value of alexithymia in patients with eating disorders: A 3-year prospective study. Journal of Psychosomatic Research, 63(4), 365371. https://doi.org/10.1016/j.jpsychores.2007.03.008

Spitzer, C., Siebel-Jürges, U., Barnow, S., Grabe, H. J., \& Freyberger, H. J. (2005). Alexithymia and interpersonal problems. Psychotherapy and Psychosomatics, 74(4), 240-246. https://doi.org/10.1159/000085148

Stice, E., Marti, C. N., \& Durant, S. (2011). Risk factors for onset of eating disorders: Evidence of multiple risk pathways from an 8-year prospective study. Behaviour research and therapy, 49(10), 622-627. https://doi.org/10.1016/j.brat.2011.06.009

Stice, E., Gau, J. M., Rohde, P., \& Shaw, H. (2017). Risk factors that predict future onset of each DSM-5 eating disorder: Predictive specificity in high-risk adolescent females. Journal of Abnormal Psychology, 126(1), 38. 10.1037/abn0000219

Storch, M., Keller, F., Weber, J., Spindler, A., \& Milos, G. (2011). Psychoeducation in affect regulation for patients with eating disorders: a randomized controlled feasibility study. American Journal of Psychotherapy, 65(1), 81-93.

Strober, M. (2004). Pathologic fear conditioning and anorexia nervosa: On the search for novel paradigms. International Journal of Eating Disorders, 35, 504-508. https://doi.org/10.1002/eat.20029

Strodl, E., \& Wylie, L. (2020). Childhood trauma and disordered eating: Exploring the role of alexithymia and beliefs about emotions. Appetite, 154, 104802. 
Svaldi, J., Griepenstroh, J., Tuschen-Caffier, B., \& Ehring, T. (2012). Emotion regulation deficits in eating disorders: a marker of eating pathology or general psychopathology? Psychiatry

Research, 197(1-2), 103-111. https://doi.org/10.1016/j.psychres.2011.11.009

Swinbourne, J. M., \& Touyz, S. W. (2007). The co-morbidity of eating disorders and anxiety disorders: A review. European Eating Disorders Review: The Professional Journal of the Eating Disorders Association, 15(4), 253-274. https://doi.org/10.1002/erv.784

Taut, D., Renner, B., \& Baban, A. (2012). Reappraise the situation but express your emotions: impact of emotion regulation strategies on ad libitum food intake. Frontiers in Psychology, 3, 359. https://doi.org/10.3389/fpsyg.2012.00359

Taylor, G. J. (2000). Recent developments in alexithymia theory and research. The Canadian Journal of Psychiatry, 45(2), 134-142. https://doi.org/10.1177/070674370004500203

Taylor, G. J., \& Bagby, R. M. (2000). An overview of the Alexithymia construct. In R. Bar-On \& J. D. A. Parker (Eds.), The handbook of emotional intelligence (pp. 40-67). San Francisco: Jossey-Bass. Tchanturia, K., Davies, H., Harrison, A., Fox, J. R., Treasure, J., \& Schmidt, U. (2012). Altered social hedonic processing in eating disorders. International Journal of Eating Disorders, 45(8), 962-969. https://doi.org/10.1002/eat.22032

Torres, S., Guerra, M. P., Lencastre, L., Miller, K., Vieira, F. M., Roma-Torres, A., ... \& Costa, P. (2015). Alexithymia in anorexia nervosa: The mediating role of depression. Psychiatry Research, 225(1-2), 99-107. https://doi.org/10.1016/j.psychres.2014.10.023

Van Durme, K., Braet, C., \& Goossens, L. (2015). Insecure attachment and eating pathology in early adolescence: Role of emotion regulation. The Journal of Early Adolescence, 35(1), 54-78. https://doi.org/10.1177/0272431614523130

Vanheule, S., Desmet, M., Meganck, R., \& Bogaerts, S. (2007). Alexithymia and interpersonal problems. Journal of Clinical Psychology, 63(1), 109-117. https://doi.org/10.1002/jclp.20324 
Venta, A., Hart, J., \& Sharp, C. (2013). The relation between experiential avoidance, alexithymia and emotion regulation in inpatient adolescents. Clinical Child Psychology and Psychiatry, 18(3), 398410. https://doi.org/10.1177/1359104512455815

Zarei, J., \& ali Besharat, M. (2010). Alexithymia and interpersonal problems. Procedia-Social and Behavioral Sciences, 5, 619-622. https://doi.org/10.1016/j.sbspro.2010.07.153

Zerwas, S., Lund, B. C., Von Holle, A., Thornton, L. M., Berrettini, W. H., Brandt, H., ... \& Kaplan, A. S. (2013). Factors associated with recovery from anorexia nervosa. Journal of Psychiatric Research, 47(7), 972-979. https://doi.org/10.1016/j.jpsychires.2013.02.011

Zigmond, A. S., \& Snaith, R. P. (1983). The hospital anxiety and depression scale. Acta Psychiatrica Scandinavica, 67(6), 361-370. https://doi.org/10.1111/j.1600-0447.1983.tb09716.x 